
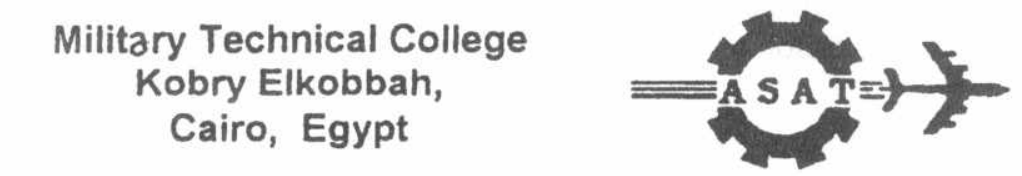

$8^{\text {th }}$ International Conference on Aerospace Sciences \& Aviation Techriology

\title{
THEORETIGAL AND EXPERIMENTAL STUDY ON DIESEL. ENGINE PERFORMANCE UNDER SYNTHETIC ATMOSPHERE FOR RECYCLE OPERATION
}

\author{
E.M.Marzouk,A.M.Nour,M.A.Awwad and A.I.Abdelfattah
}

Mechanical Engineering Dept. , Faculty of Engineering,

Abstract :

Alexandria University, Alexandria, Egypt

The closed cycle diesel engine provides an economic solution to fill the strongly needed energy gap for naval submarine between the low performance conventional diesel electric system and the high performance nuclear reactor plant. The interrelationships between the non-air oxidants with moderate gases for synthetic atmosphere and engine performance, are either not well documented or understood.

A theoretical model based on fuel/synthetic atmosphere cycle approximation for the diesel engine, is developed. Model results show direct reflection of the intake gas mixture constituents effects without the uncertainties associated with the combustion process for actual cycle modeling under synthetic atmosphere. This necessitates the generation of temperature entropy charts for both synthetic atmosphere and corresponding combustion gases. The charts and engine cycles presentation are programmed for PC with sufficient generality to represert any synthetic atmosphere constituents and under different excess synthetic atmosphere factors.

An experimental rig, including single cylinder diesel engine, gas metering apparatus and instruments, is designed, constructed and employed to provide results for comparison. The performance deteriorating effects due to $\mathrm{CO}_{2} \%$ increase by volume and the beneficial effects due to $\mathrm{O}_{2} \%$ increase by volume, in the engine inlet mixture, are analyzed. The theoretical rnodel results, show satisfactory correlation with the experimental results and/or previous works.

Keywords: Diesel engine, Synthetic atmosphere, Theoretical, Experimental

\section{Nomenclature:}

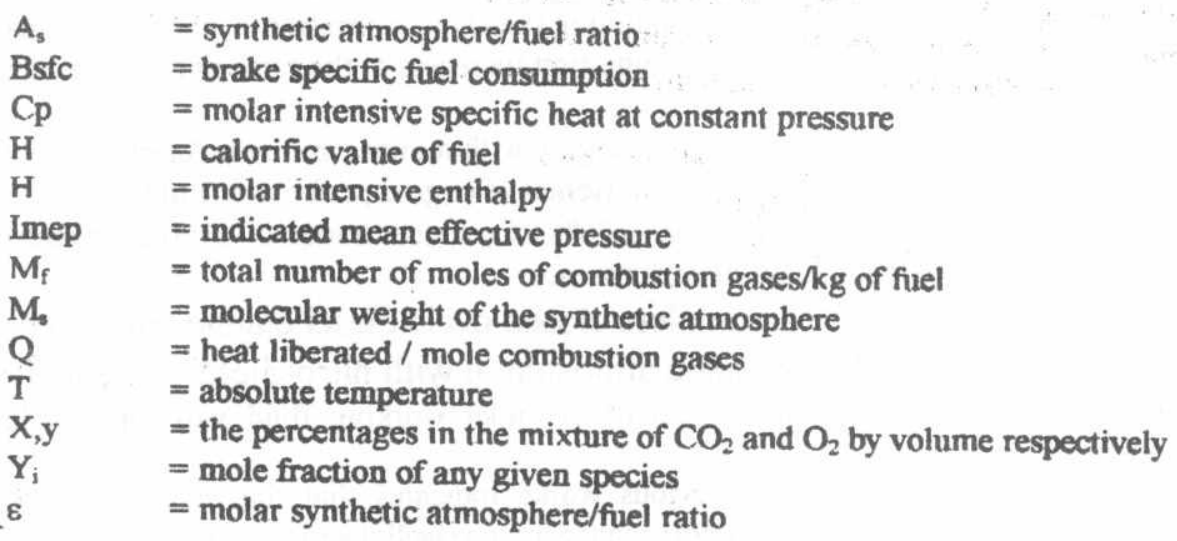


$\begin{array}{ll}v_{\mathrm{i}} & =\text { species moles of combustion products } \\ \lambda_{\mathrm{s}} & =\text { excess synthetic atmosphere factor }\end{array}$

\author{
subscripts: \\ th, act Denote theoretical and actual respectively \\ $\mathrm{i} \quad$ Specify any given species $1,2,3, \ldots \ldots . \mathrm{j}$ \\ m Denotes mixture \\ s Denotes synthetic
}

\title{
Introduction:
}

The energy capacity of conventional electric powered submarine is only sufficient to allow undersea missions of about $\mathbf{4 8}$ hours, to be carried out before the storage batteries are to be recharged oversea or under snorkel mode $[1,2,3]$. On the other hand, the nuclear submarine can access almost limitless power. However, it is not available for all navies for economical or strategic reasons. It is also too large and noisy for shallow seas [4]. Thus, there is a strong need for a power system that can fill the energy gap between the low performance conventional diesel electric battery system and the high performance nuclear reactor base plant. The submerged endurance is of fatal importance in submarine effectiveness. Alternative systems have been proposed and the closed cycle diesel engine system provides the economical solution to fill this gap $[1,5,6,7]$. The engine, then, has to make use of synthetic atmosphere of oxygen and managed exhaust gases. The size of the exhaust gas management system is a direct reflection of the partial pressure of the $\mathrm{CO}_{2}$ in the working fluid. The higher the concentration of $\mathrm{CO}_{2}$, the greater the possible separation and removal and hence the smaller the management system $[8,9]$. The non-air breathing diesel may also be used in industrial applications where contamination of air supply is a practical possibility like in mines, industrial and chemical plants and nuclear power plants...etc. [10]

Karim [10] analyzed experimentally the effect of unconventional atmosphere on diesel engine performance. He created the atmosphere by the addition of contamination gases such as $\mathrm{CO}_{2}, \mathrm{~N}_{2}$ or $\mathrm{O}_{2}$ to the air intake change. The engine tolerated admission of $\mathrm{CO}_{2}$ concentration up to $16 \%$ by volume. However, the $\mathrm{CO}_{2}$ increase means, in effect, a reduction in the actual quantity of $\mathrm{O}_{2}$ inhaled by the engine.

Zheng et al $[11,12,13,14]$ made a theoretical and experimental work to study the effect of synthetic atmosphere on diesel engine performance. An imperical formula for the heat release was used in the actual cycle simulation program. The gravimetric concentration of $\mathrm{O}_{2}$ was maintained fixed at $23 \%$ while increasing the $\mathrm{CO}_{2}$. The IDI diesel engine with compression ratio of 23 , continued running untill $\mathrm{CO}_{2} . \%$ by mass of $45 \%$. At about $50 \% \mathrm{CO}_{2}$, there was a sudden loss in performance. It is emphasized that maintaining the $\mathrm{O}_{2} \%$ concentration constant by mass in the studies means, in effect, that the $\mathrm{O}_{2}$ mass ingestion increases at the same engine speed and fueling rate.

Hawley [15] used a 4-cylinder diesel engine with number one cylinder operating on non-air atmosphere. This provision enabled the extremes of engine performance to be observed. $\mathrm{He}$ reported achieving engine operation with up to $70 \% \mathrm{CO}_{2}$ concentration by charge preheating to $15 \mathrm{O}^{\circ} \mathrm{C}$. He observed severe degradation in performance.

Fowler [16] developed a complete closed cycle diesel engine. He reached only $4 \% \quad \mathrm{CO}_{2}$ by volume in the synthetic atmosphere with nitro-diesel system. The main restriction was the specific heat ratio of the inlet working fluid with the exhaust management system.

The overall implication of the previous works indicates that the interrelationships between the non-air oxidants and engine's performance are not well documented nor understood. 
The complexity of the combustion process under synthetic atmosphere with the uncertainties associated with the mixing, kinetics of reaction, non-equilibrium effects, heat release data as well as heat transfer data. ... etc. would have made using the presently developed actual cycle simulation models, practically impossible to be justified at least untill adequate data becomes available. A fuel/synthetic atmosphere cycle approximation is, therefore, developed that directly reflects the effects of synthetic constituents variation.

Hence, the present work was established with the overall objective of delineating. assessing and determining the theoretical and experimental performance of diesel engine when operating in non-air mixtures based on using $\mathrm{CO}_{2}$ as moderating gas and $\mathrm{N}_{2}$ as top up gas.

\section{Experimental System:}

To validate the theoretical model, a fully instrumented test rig, with a precise control system, was designed and constructed. The synthetic atmosphere was produced from mixing of bottled gases in the gas mixing unit, after being metered by choked nozzle meters as shown in Fig (1). The oxygen, the moderating gas and top up gas are fed to the mixing unit via a system of needle control valves; both coarse and fine. The choked nozzles were calibrated for air, $\mathrm{O}_{2}, \mathrm{~N}_{2}$ and $\mathrm{CO}_{2}$ to cover all the envisaged flow combinations. The variation of the combined gas flow rates allows for complete fluid control over the engine intake operational requirements. The system can accurately supply a wide variety of different atmospheres to the engine at preset flow rates, pressures and temperatures which are independent of ambient conditions. Full details of the experimental set up can be obtained from (17). The test engine is $795 \mathrm{~cm}^{3}$, single cylinder, air cooled, Robur indirect injection diesel engine, with compression ratio of 18 . An electric dynamometer with motoring capability provides the engine load. The engine has been operated with variety of $\mathrm{CO}_{2} / \mathrm{O}_{2} / \mathrm{N}_{2}$ concentrations mixtures by volume over its full power range at selected speeds. It has also been operated on conventional fuel/air mixtures so as to produce base line engine data for comparison. The system is designed to allow engine to operate in either air or synthetic atmosphere mode, with the ability to switch quickly between these two operating mocles. Error analysis in measuring static pressure, differential pressure, total temperature are estimated as .05 bar and $.01{ }^{\circ} \mathrm{K}$. Uncertainties in measuring orifice air flow rates are within 0.8 and $2.7 \%$ while these for choked nozzle gases flow rates are within $2.8 \%$.

\section{Theoretical Model:}

The engine cylinder gases are assumed to be a mixture of $\mathrm{O}_{2}, \mathrm{~N}_{2}$, fuel vapor, $\mathrm{CO}_{2}$, water vapor and residual gases. The synthetic atmosphere/fuel ratio may be changed during engine operation. The synthetic atmosphere and its corresponding combustion gases are assurned to be thermally perfect gas, i.e. the gas mixture obeys the thermal equation of state but it is calloricaly imperfect. The variation of the number of moles due to combustion is also taken into account. Complete combustion is assumed and starts at top dead center. However, the effect of dissociation is not included since the temperature is not likely to reach that limit[17]. The stoichiometric combustion equation for the fuel $\left(\mathrm{C}_{\alpha} \mathrm{H}_{\beta}\right)$ in the synthetic atmosphere that composed of $\mathrm{O}_{2}$ gas, moderate gas $\mathrm{CO}_{2}$ and $\mathrm{N}_{2}$ as top up gas, may be written as:

$$
\mathrm{C}_{\alpha} \mathrm{H}_{\beta}+\varepsilon\left[\mathrm{xCO}_{2}+\mathrm{yO}_{2}+(1-\mathrm{x}-\mathrm{y}) \mathrm{N}_{2}\right] \rightarrow v_{1} \mathrm{CO}_{2}+v_{2} \mathrm{H}_{2} \mathrm{O}+v_{3} \mathrm{~N}_{2}
$$

The atoms conservation give :

$$
\begin{array}{ll}
v_{1} & =\alpha+\varepsilon x \\
v_{2} & =\beta / 2 \\
v_{3} & =\varepsilon(1-x-y)
\end{array}
$$




$$
\varepsilon \quad=(x+0.25 \beta) / y
$$

Defining the excess synthetic atmosphere factor $\lambda_{3}$ as :

$$
\left.\left.\lambda_{\mathrm{s}} \quad=\mathrm{A}_{\mathrm{s}}\right)_{\text {act }} / \mathrm{A}_{\mathrm{s}}\right)_{\text {th }}
$$

$\left.A_{s}\right)_{\text {th }} \quad=$ the theoretical synthetic atmosphere-fuel ratio

$$
=\varepsilon \mathrm{M}_{s}(12 \alpha+\beta)
$$

For diesel engine where the inlet mixture is always lean, $\lambda_{3}>1$ and the diesel fuel with the chemical composition $\mathrm{C}_{14.4} \mathrm{H}_{24.9}$, the combustion eqn., then, becomes [18]:

$$
\begin{aligned}
& \mathrm{C}_{14.4} \mathrm{H}_{24.9}+\lambda_{s} \varepsilon\left[\mathrm{y} \mathrm{O}_{2}+\mathrm{x} \mathrm{CO}+(1-\mathrm{x}-\mathrm{y}) \mathrm{N}_{2}\right] \rightarrow \rightarrow \\
& v_{1} \mathrm{CO}_{2}+v_{2} \mathrm{H}_{2} \mathrm{O}+v_{3} \mathrm{~N}_{2}+v_{4} \mathrm{O}_{2}
\end{aligned}
$$

The number of moles of mixture $\mathrm{N}$ of the synthetic atmosphere or that of combustion products is the sum of all moles " $\mathrm{j}$ " components:

$$
\mathrm{N}=\sum_{\mathrm{i}=1}^{\mathrm{j}} v_{\mathrm{i}}
$$

The molecular weight of the mixture $\mathrm{M}$

$$
\mathbf{M}_{m}=\sum_{i=1}^{j} y_{i} \quad M_{i}
$$

where $y_{i}$ is the mole fraction of any given species

$$
\mathrm{y}_{\mathrm{i}}=\mathrm{v}_{\mathrm{i}} / \mathrm{N}
$$

The molar specific heat at constant pressure of the mixture is:

$$
C p_{m}=\sum_{i=1}^{j} y_{i} C p_{i}
$$

The molar specific heats at constant pressure are available in the JANAF tables (18). The specific heats are curve fitted for computer to polynomials by minimizing least-square error. The function for any given species is in the form:

$$
\mathrm{Cp}(\mathrm{T})=\mathrm{a}+\mathrm{bT}+\mathrm{cT}^{2}+\ldots \ldots \ldots+\mathrm{k} \mathrm{T}^{10}
$$

The constants for different species are obtained for the temperature ranges of $300-1000{ }^{\circ} \mathrm{K}$ and $1000-3000^{\circ} \mathrm{K}$, and the enthalpy is then obtained :

$$
\mathrm{h}=\int_{\mathrm{T}_{1}}^{\mathrm{T}_{2}} \mathrm{Cp} \mathrm{dT}=\left[\mathrm{aT}+1 / 2 \mathrm{bT} 2+\ldots . .+1 / 10 \mathrm{jT}^{10}+1 / 11 \mathrm{kT}^{11}\right]_{\mathrm{T}_{1}}^{\mathrm{T}_{2}}
$$

The constant volume lines, the constant pressure lines and the energy lines are, then, constructed or temperature entropy chart based on the following reference conditions where the entropy is taken as zero $[19,20]$ :

$$
\mathrm{T}_{\mathrm{o}}=300^{\circ} \mathrm{K}, \mathrm{P}_{\mathrm{o}}=1.0 \mathrm{Bar}, \mathrm{V}_{\mathrm{o}}=25.41 \mathrm{~m}^{3} / \mathrm{mole}
$$

Fig (2) and Fig (3) show a sample of the generated temperature entropy chart for synthetic atmosphere that consists of $30 \% \mathrm{CO}_{2}, 21 \% \mathrm{O}_{2}$ and the remainder is $\mathrm{N}_{2}$ by volume per mole and the corresponding chart for combustion gases per mole combustion gases at excess synthetic atmosphere factor $\lambda_{3}=1.5$, respectively.

The total heat liberated from combustion per mole of combustion gases is :

$$
\mathrm{Q}=\mathrm{H} / \mathrm{M}_{\mathrm{f}}
$$


A computer program is written with sufficient generality to generate the diesel cycle with process iterations for any in cylinder composition, any excess synthetic atmosphere factor and certain compression ratio as shown in Fig $(2,3)$.

\section{Results and Discussion :}

Model results for an air cooled diesel engine having compression ratio of 18 , synthetic atmosphere factor $\lambda_{2}=1.5$ and for constant oxygen concentration of $21 \%$ by volume in the engine intake are shown in figures (4) and (5). The incylinder parameters deterioration due to the increase of $\mathrm{CO}_{2} \%$ concentration by volume in the synthetic atmosphere are shown in Fig.(4). The deterioration is attributed, in principle, to the reduced specific heat ratio of the intake synthetic atmosphere. The overall implication is shown in corresponding deterioration of performance parameters of the engine in fig (5). It should be noticed that the rate of deterioration of the indicated mean effective pressure and other performance parameters, is decreased with the increase in $\mathrm{CO}_{2} \%$ in the intake mixture. It appears from figure (6) that the load increase (i.e. $\lambda_{3}$ decrease ) results in output power enhancement when related to that of normal air. The equivalence compression ratio Fig (7) is shown to decrease by the increase of $\mathrm{CO}_{2} \%$ in the mixture, that is the $\mathrm{CO}_{2}$ contamination is equivalent to decrease in engine compression ratio. It is also shown that the $\mathrm{CO}_{2}$ contamination in intake mixture affects both the compression process as well as the first phase of heat addition process. Figure (8) indicates that the mixture enrichment with oxygen can recover, in effect, performance deterioration due to $\mathrm{CO}_{2}$ contamination. The cycle maximum pressure and temperature of incylinder gas increase and the corresponding beneficial effects on performance parameters are detailed on figures (8) and (9). This improvement is attributed to the decrease in the total number of moles of combustion gas products. This implies increase in the heat released from fuel per mole combustion gases. Oxygen enrichment of the intake mixture, however, does not affect the mixture specific heat ratio but strongly affects the first phase of heat addition with no effects on the compression process as shown in fig (10). This means that the performance enhancement due to $\mathrm{O}_{2}$ enrichment in a certain $\mathrm{CO}_{2}$ contaminated atmosphere, is achieved provided the fuel would reach the self ignition temperature and burns.

It is emphasized here that studying the effects of $\mathrm{CO}_{2} \%$ by mass increase while maintaining oxygen concentration constant at $23.3 \%$ such as those done by $[12,13]$ and others, leads to an increase of the actual quantity of oxygen admitted to the cylinder. This is because the $\mathrm{CO}_{2}$ is a weighty gas compared to $\mathrm{O}_{2}$ or $\mathrm{N}_{2}$. Hence, maintaining $\mathrm{O}_{2} \%$ by mass constant does not represent an adequate way to analyze the effects of $\mathrm{CO}_{2}$ contamination on engine performance . The fresh charge suction process of the engine is volume restricted and not mass restricted process. Comparison of performance results predicted on the two basis are shown in fig (11).

A series of engine load characteristics under constant speed operation, are experimentally carried out with increasing engine intake percentage volume concentration of $\mathrm{CO}_{2}$. Figure (12) presents the brake specific fuel consumption against brake power for engine operation under different synthetic atmospheres of different $\mathrm{CO}_{2} \%$ by volume and under constant $\mathrm{O}_{2}$ of $21 \%$ by volume. The figure also shows the results of the base line engine under normal air operation. It appears that at high load, maintaining oxygen concentration by volume constant at $21 \%$ and increase of $\mathrm{CO}_{2} \%$ by volume of the engine intake charge to up to $24 \%$, there is only slight increase in bsfc. At idling and low loads, on the other hand, the increase in bsfc is remarkable with $\mathrm{CO}_{2} \%$ increase upto $20 \%$ and the engine runs stable. Reaching $24 \% \mathrm{CO}_{2}$, it is noticed that the engine runs rough, unstable and the noise level increased. At $25 \% \mathrm{CO}_{2}$. sudden loss in performance is noticed which may be attributed to 
ignition failure at this high level of $\mathrm{CO}_{2} \%$ content. Figure (13), on the other hand, presents the effect of $\mathrm{O}_{2} \%$ by volume mixture enrichment of $25 \%$. The engine, then, continues to run stable with $\mathrm{CO}_{2} \%$ in the mixture up to $28 \%$ with improved bsfc at all loads. Overall implication shows that the experimental results compares satisfactorily with the corresponding theoretical mode results.

\section{Conclusion:}

1. A theoretical model based on the fuel/synthetic atmosphere cycle approximation for diesel engine, is developed. The temperature - entropy charts and engine cycle presentation are programmed for P.C. with sufficient generality to represent any synthetic atmosphere constituents and under different excess synthetic atmosphere factors. Model results reflects intake mixture constituents effects and compares satisfactorily with experimental results. The model proved to be valuable predictor tool for determination of the deteriorating effects of $\mathrm{CO}_{2}$ contamination and the beneficial effects of $\mathrm{O}_{2}$ enrichment for real engine performance.

2. Reporting performance deteriorating effects or beneficial effects due to $\mathrm{CO}_{2} \%$ contamination by mass and due to $\mathrm{O}_{2} \%$ enrichment by mass, respectively is inadequate.

3. Increase of $\mathrm{O}_{2} \%$ in the engine intake working fluid enhances its performance provided the fuel would reach the self ignition temperature. Under certain conditions of $\mathrm{O}_{2}$ enrich.ments, the performance of engine may, reach higher levels compared to that of using normal air.

4. Development of a complete recycle diesel engine having good performance along the present reported lines makes a viable proposition provided an adequate exhaust management system is available.

\section{References:}

1. Reader, G.T., Hawley, J.G. and Walker, G., Power Plant Development for Underwater Naval Vehicles up to 3000 t Displacement", Trans. I.Mar..Mar.E.,E., Vol 102, Part 5, pp. 345-362, 1990.

2. Reader, G.T. and Potter, I.J, "Underwater Heat Engine-State of the Art", Emergency Energy Technology Symposium, ASME, 1992.

3. Reader, G.T. and Potter, I.J., "Heat Driven Power Systems for Small Autonomous Underwater Vehicles", Proceedings, 3rd Conference on Military Robotic Applications, Sept, 1991

4. Polman, N., "Atomic Submarine", Van Norstad Co. Ltd (Canada), 1963.

5. Prins, C.A. and Stapersma, D., "Atmosphere Independent Propulsion (AIP) for Ocean Going Submarines", Proceedings, Int. Conference on Submarine Systems, U-90-Stokholm, May, 1996.

6. Alling, T., Corlqvist, S. and Torestensson, B., "Small Size Power Source for Underwater Applications", Proceedings, Int. Conf. on Submarine Systems", U-90-Stokholm, May, 1990.

7. Potter, I., Schipolt, M., et al, "The Evaluation of the Performance of a Diesel Engine when Operating on Non-Air Mixtures", Proceedings, 26th Intersociety Energy Conversion Engineering Conference, Boston, Mass., Aug., 1991.

8. Reader, G.T., Zheng, H. and Hawley, J.G, "Investigation of Non-Air Diesel Engine Systems", Proceedings, IECES, San Diego, Aug, 1992.

9. Reader, G.T. and Potter, I.J., "Development of IDI Diesel Engine Test Facility for Use With Non Conventional Atmospheres, Proceedings IECEC, 1992.

10.Karim, D.G. and Satterford, T., "Performance of C.I. Engine in Unconventional Atmospheres", The Engineer, Tech. Section, pp 473-479, 1996.

11.Zheng, M. Reader, G. T and Gustafson, R., "A Thermodynamic Model of an Air Indepenclent IDI Diesel System", Proceedings, 27th IECEC, San Diego, 1992. 
12.Zheng, M., Reader, G.T., Potter, I and Gustafson, R., "Diesel Engine Performance with $\mathrm{CO}_{2} / \mathrm{O}_{2} / \mathrm{N}_{2}$ Mixtures", Second Asian Pacific Int. Symposium on Combustion and Energy, Beijing China, 1993.

13.Zheng, M. Reader, G.T., Potter, I., and Gustafson, R. "Predicting the Effects of NonConventional Atmospheres on the Performance of an IDI Diesel Fugine System", The Combustion Inst., Canadian Section, Spring Tech. Meeting, May 1992.

14.Zheng, M., Potter, I., and Hawley, I. "Preliminary Investigation of Cycle to Cycle. Variation in Non-Air Breathing Diesel Engine", Proceedings, 28th IECEC, Attanta, Ga, 1993.

15.Hawley, I.G., Ashcroft, S. and Patric, M., "Diesel Engine Research for Underwater Applications", Royal Naval Engineering, Trans IMarE, Vol 106 Part 2, pp 61-75, 1994.

16.Fowler,G. “ Closed Cycle Diesel Engine for Undersea Power”, Trans. I. Mar. E.,pp.47,1984.

17.Nour, A.M.,et al, "Theoretical and Experimental Study on Diesel Engine Performance Under Synthetic Atmosphere for Recycle Operation", M. Sc. Thesis, Dept. of Mech. Eng., Alexandria University, Nov., 1997.

18.Ferguson, C.R., "Internal Combustion Engines, Applied Thermosciences", John Wiley \& Sons, New York N.Y., 1987.

19.Mattingly, J.D., "Elements of Gas Turbine Propulsion", McGraw Hill Inc., 1996.

20.Mckinney, J.S., "Simulation of Turbotan Engine", AFAPL-TR-67-125, Air Force. AeroPropulsion Lab., Wright Patterson, OH, 1967. 


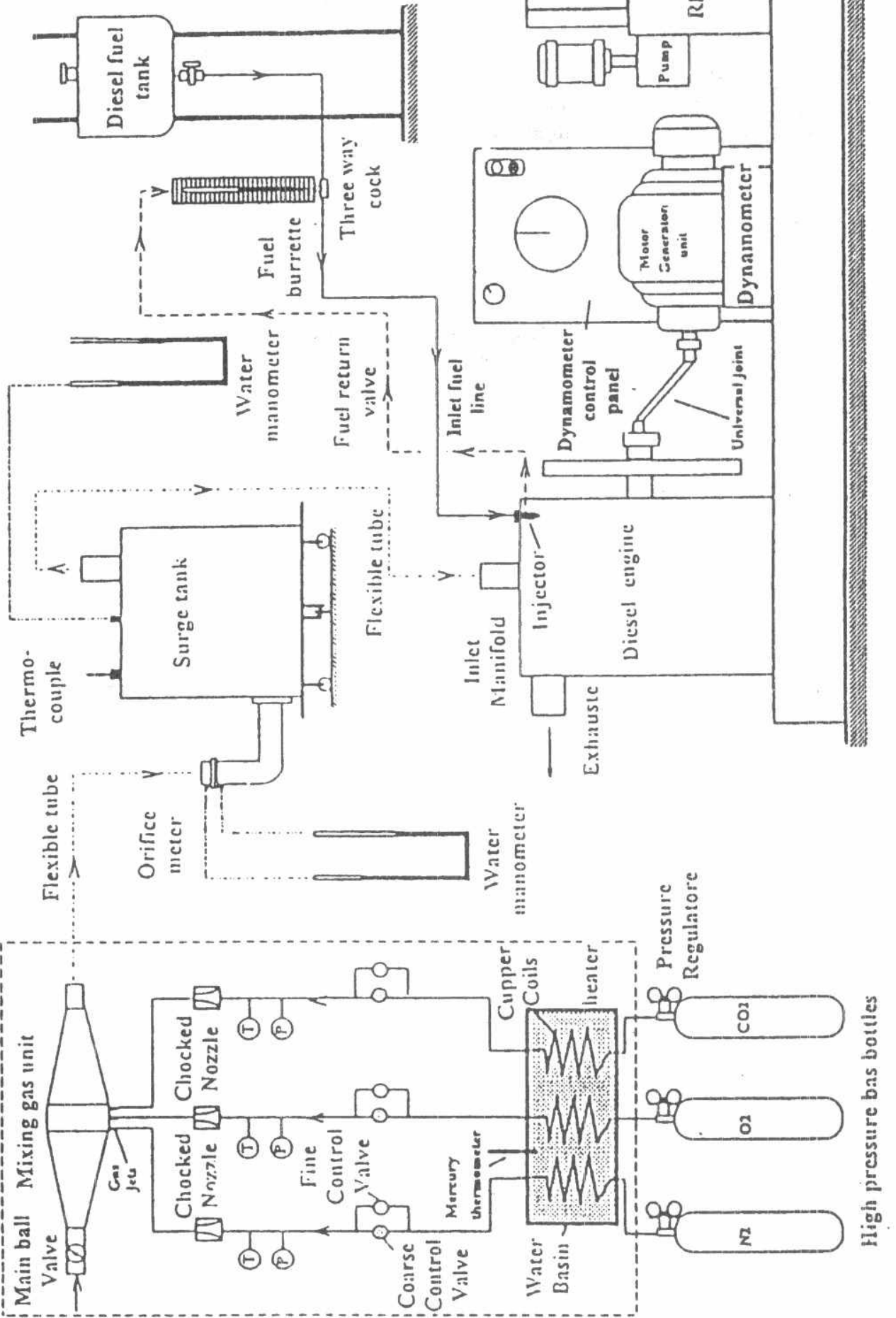

染 


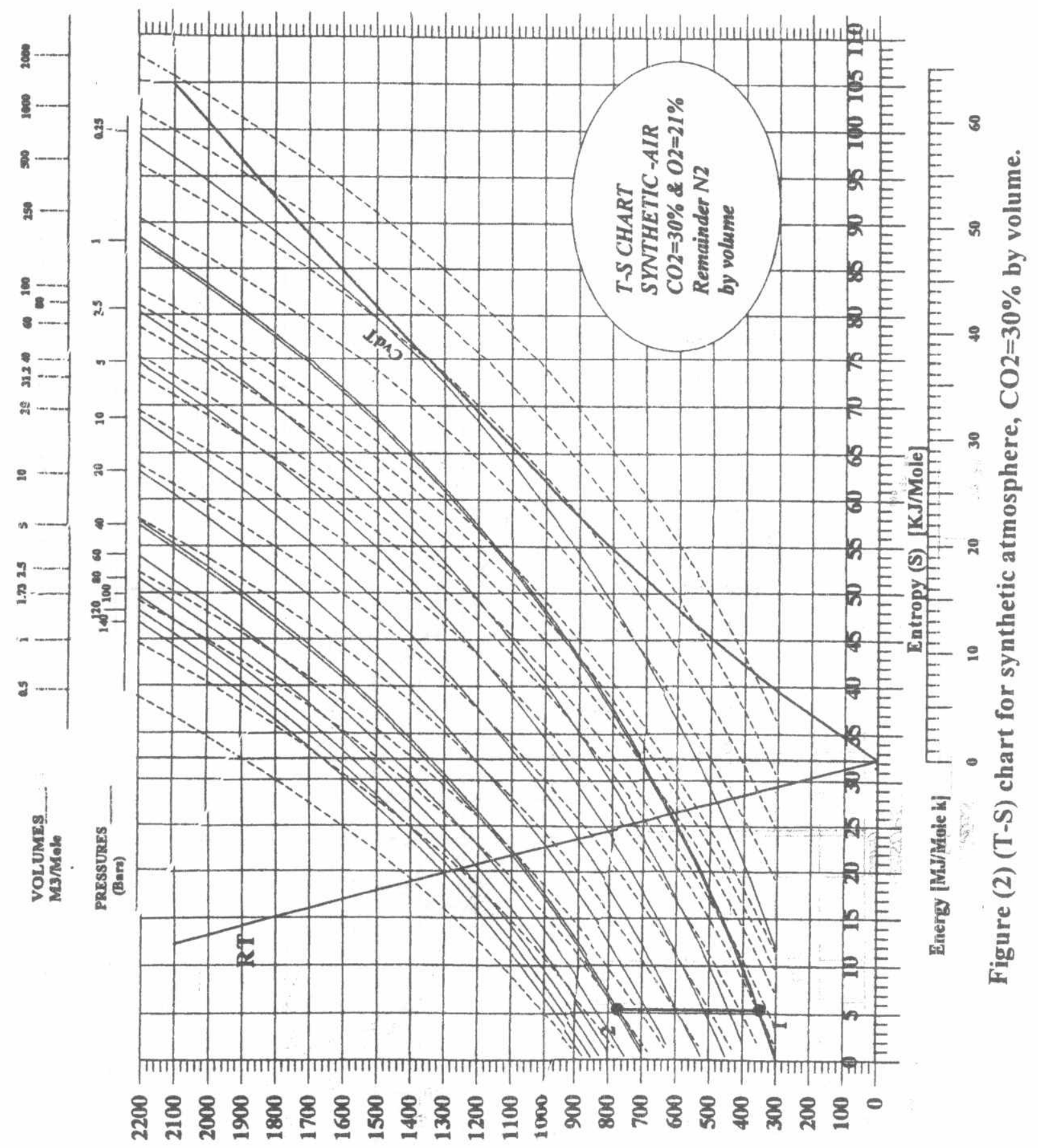

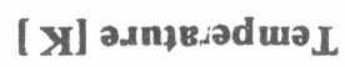



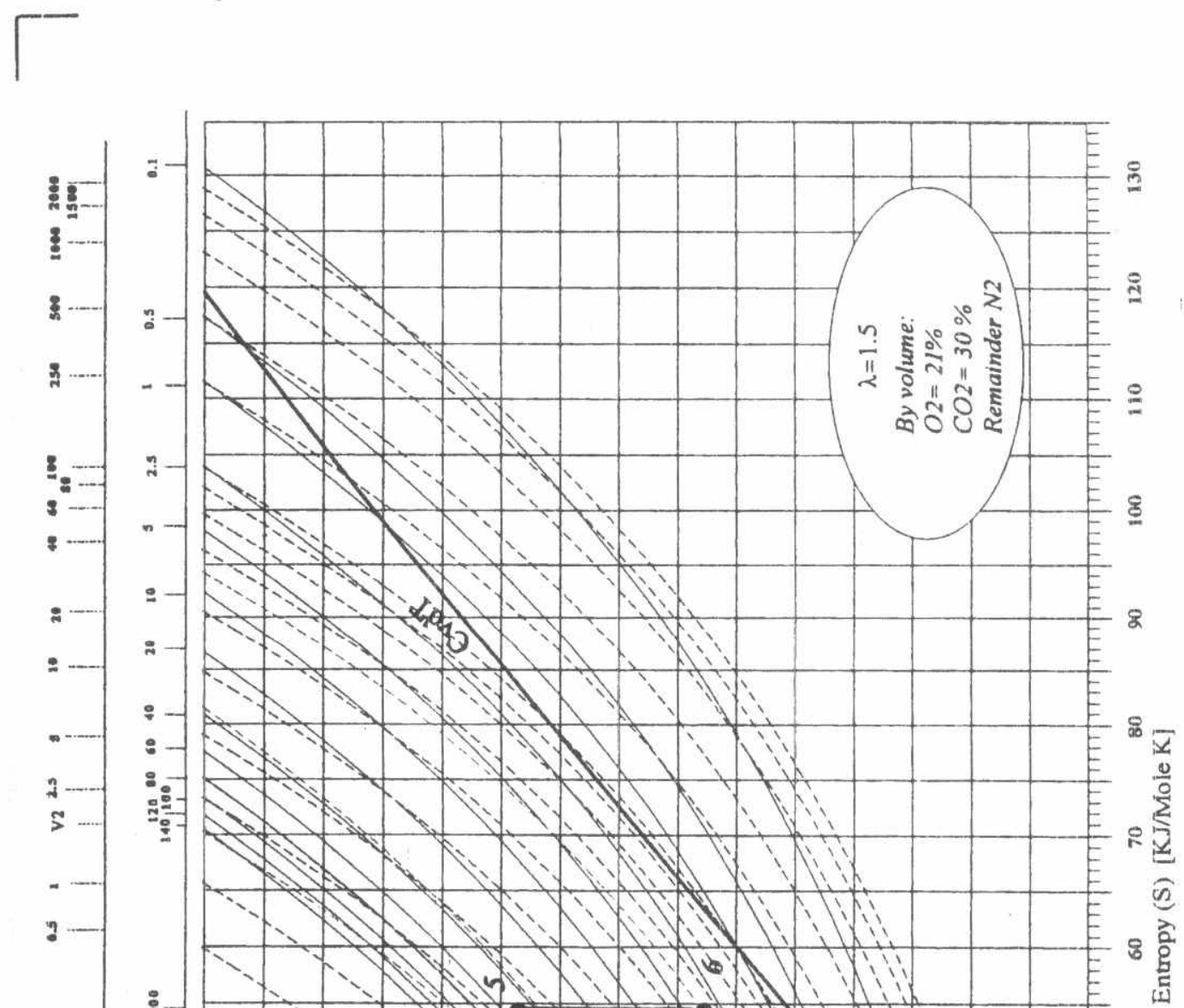

$\pi$

$\underline{8}$

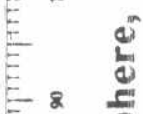

E

\&

$E$

$+2$

8

- 0

$-8$

-

-

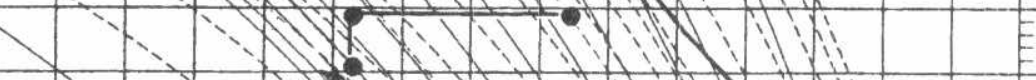

$:-$

1

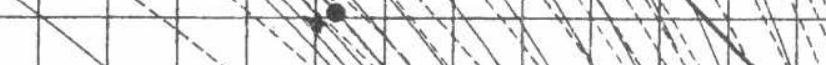

或
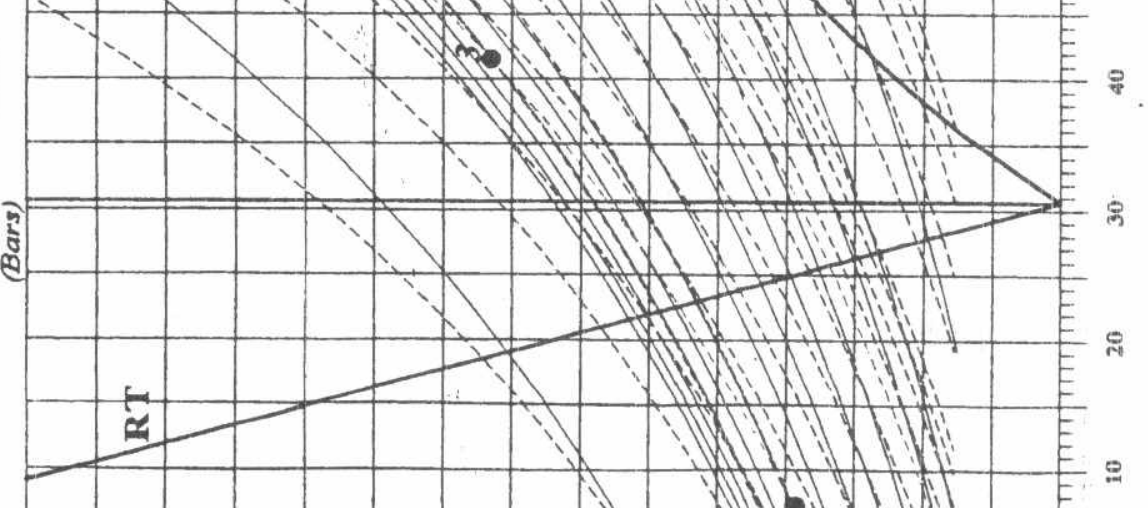

ఏิ

है

ํㅗำ

Tाm

$\div 2$

E

-

근돈

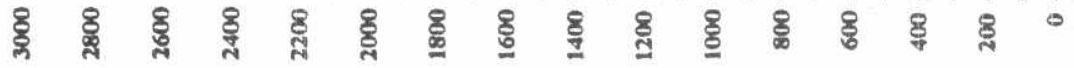

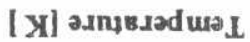

กับ 


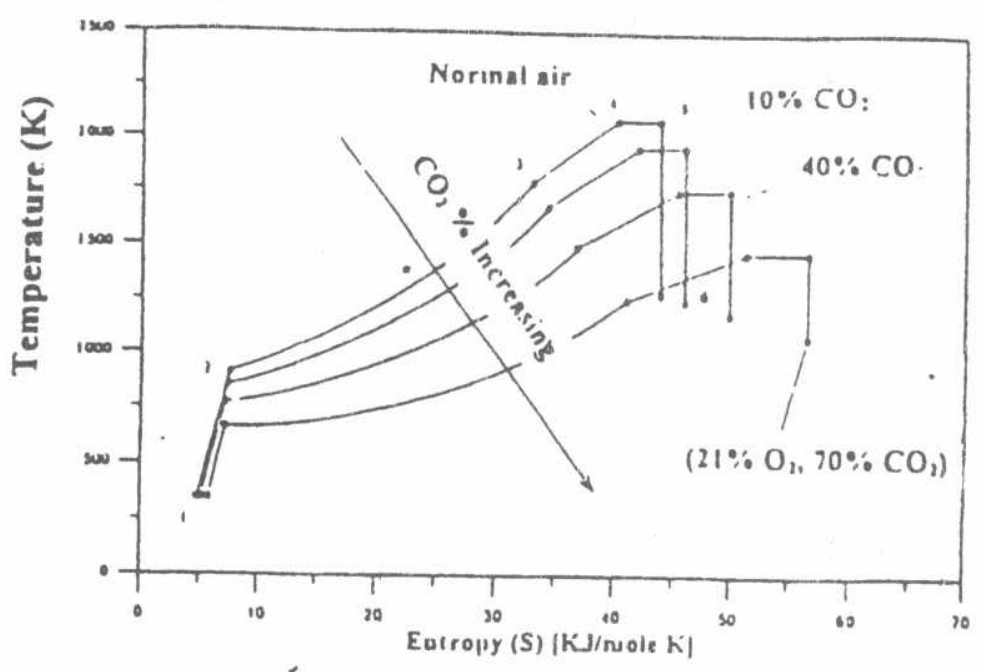

(a)

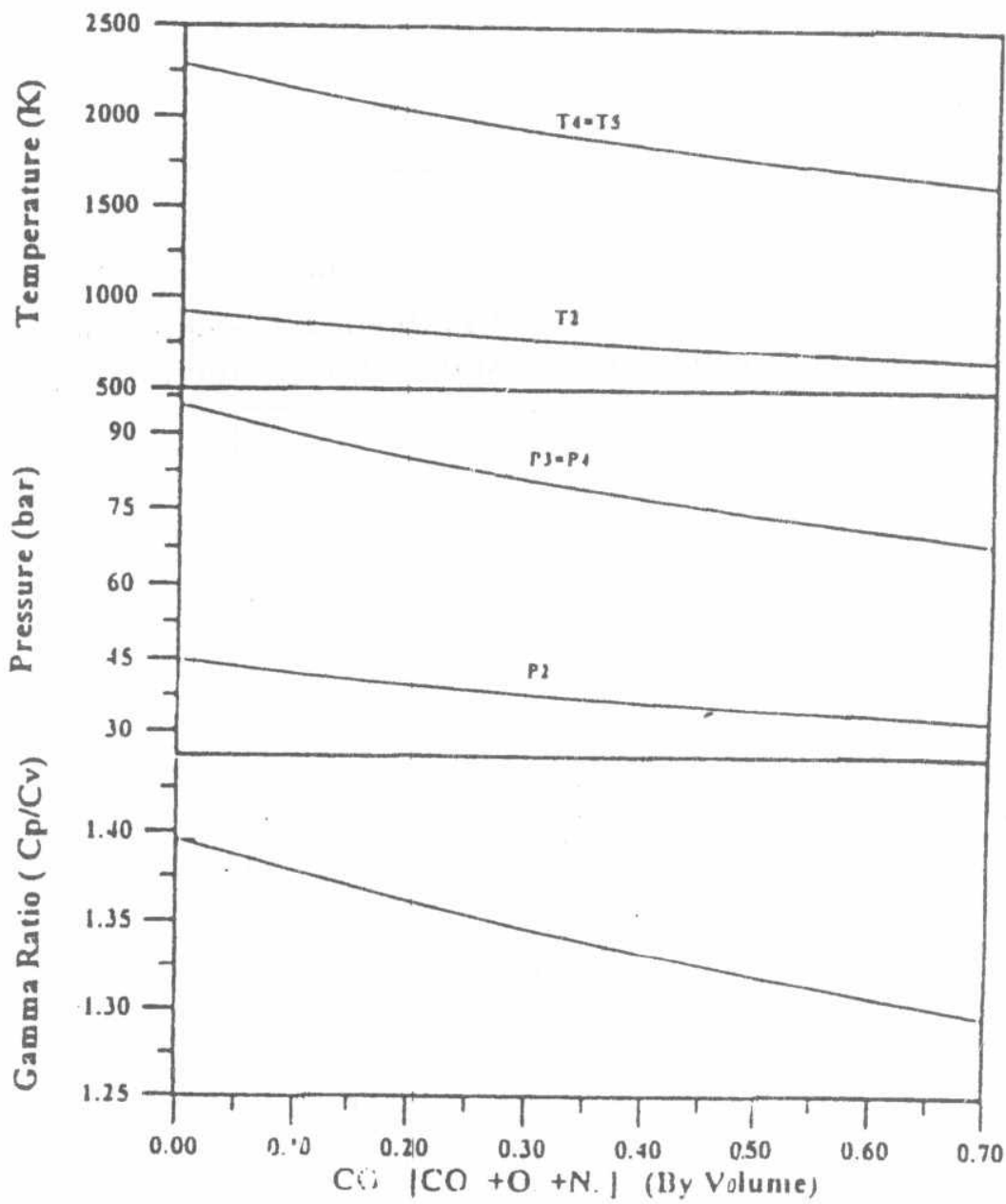

(b)

Figure (4) Effect of $\mathrm{CO}_{2} \%$ increase in synthetic atmosphere for constant $21 \% \mathrm{O}_{2}$ (by volume) on :
a) Engine T-S cycle
b) Incylinder parameters 


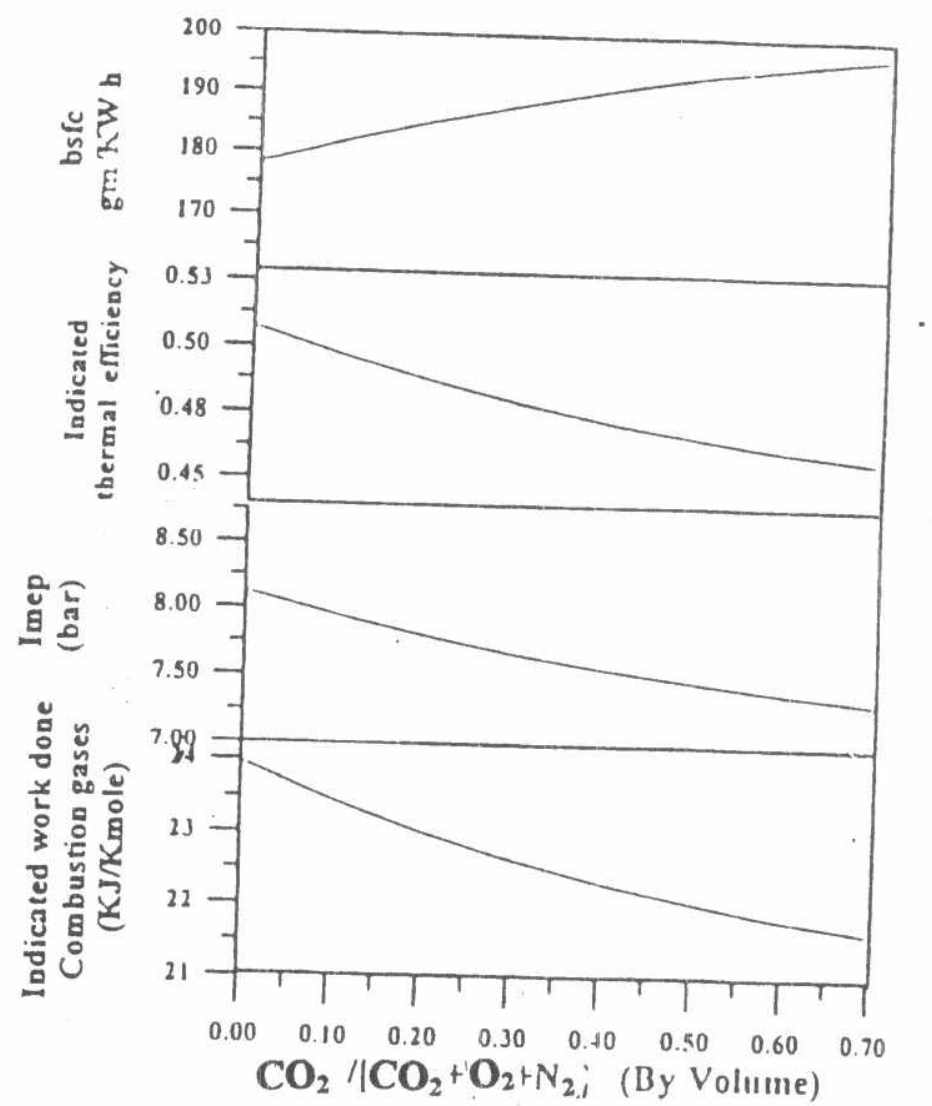

Figuer (5) Effect of $\mathbf{C O}_{2} \%$ increase in synthetic atmosphere, on performance parameters, for constant $21 \% \mathrm{O}_{2}$ (by volume)

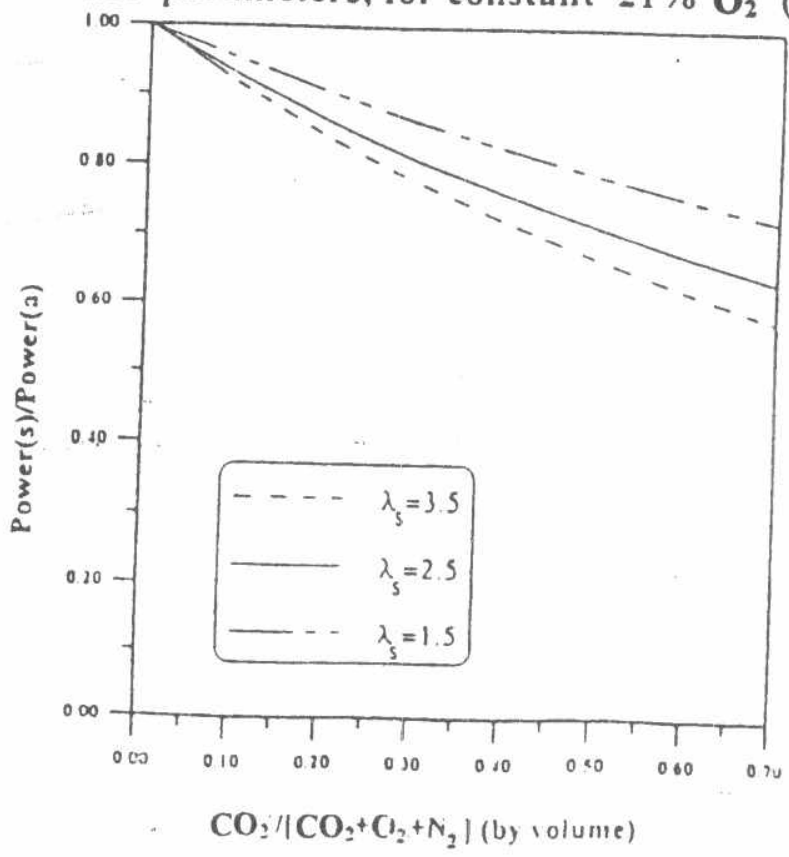

Figuer (6) Effect of $\mathrm{CO}_{2} \%$ increase in synthetic atmosphere of constant $21 \% \mathrm{O}_{2}$ (by volume) on power output. 


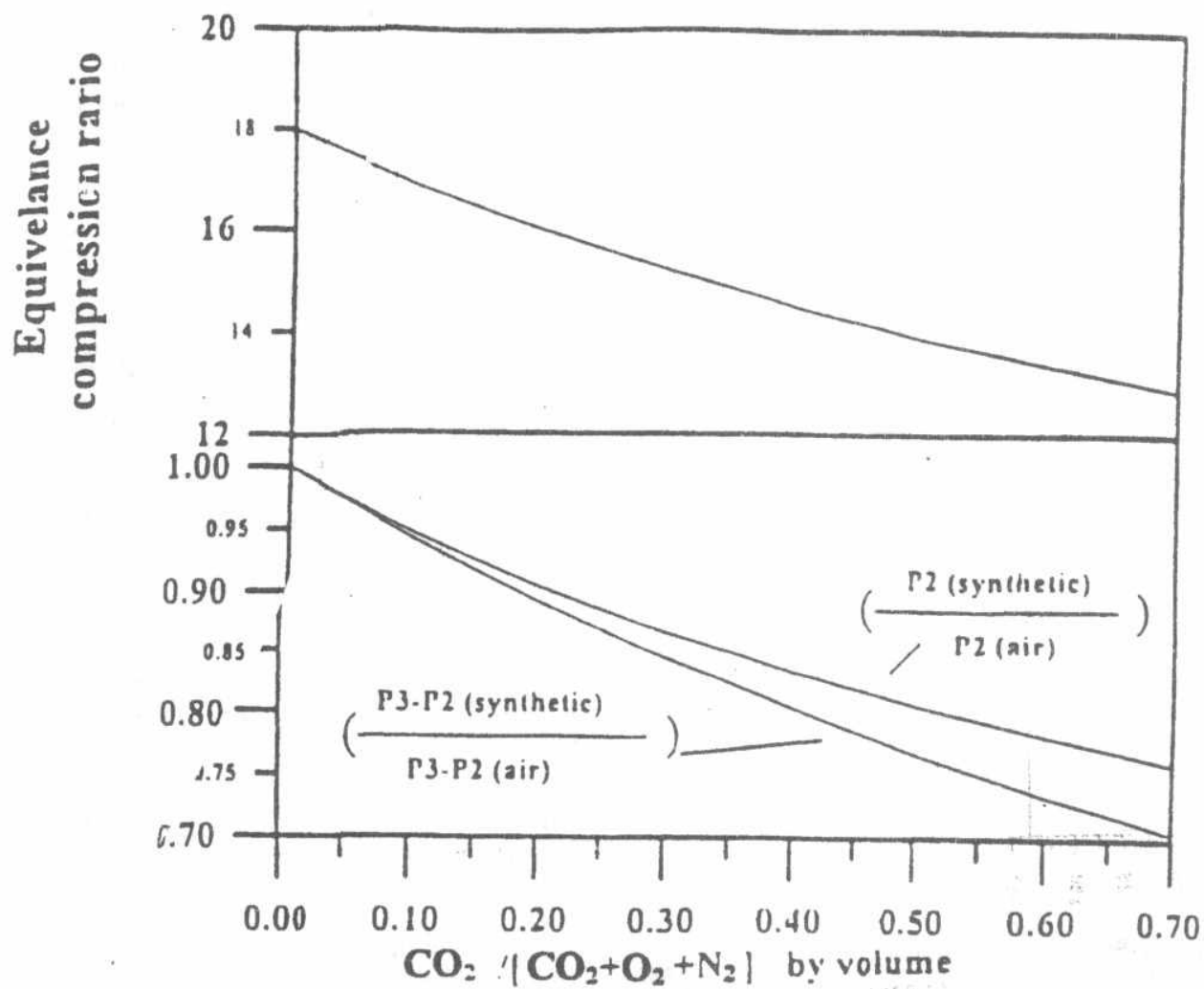

Figure (7) Effect of $\mathrm{CO}_{2} \%$ increase in syathetic atmosphere e on ead of compression and maximum pressures for constant $21 \% \mathrm{O}_{2}$ : (by volume). Also the equivelance compression ratio is shown.

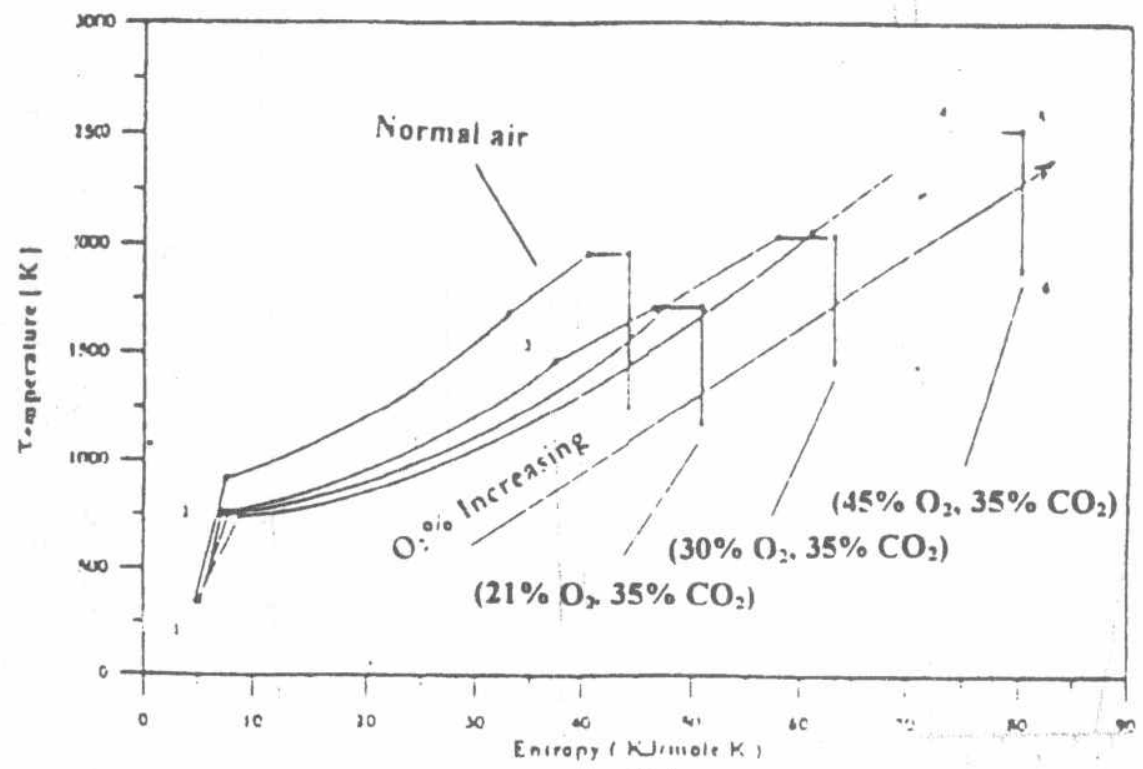

(a)

Figure (8) continued 


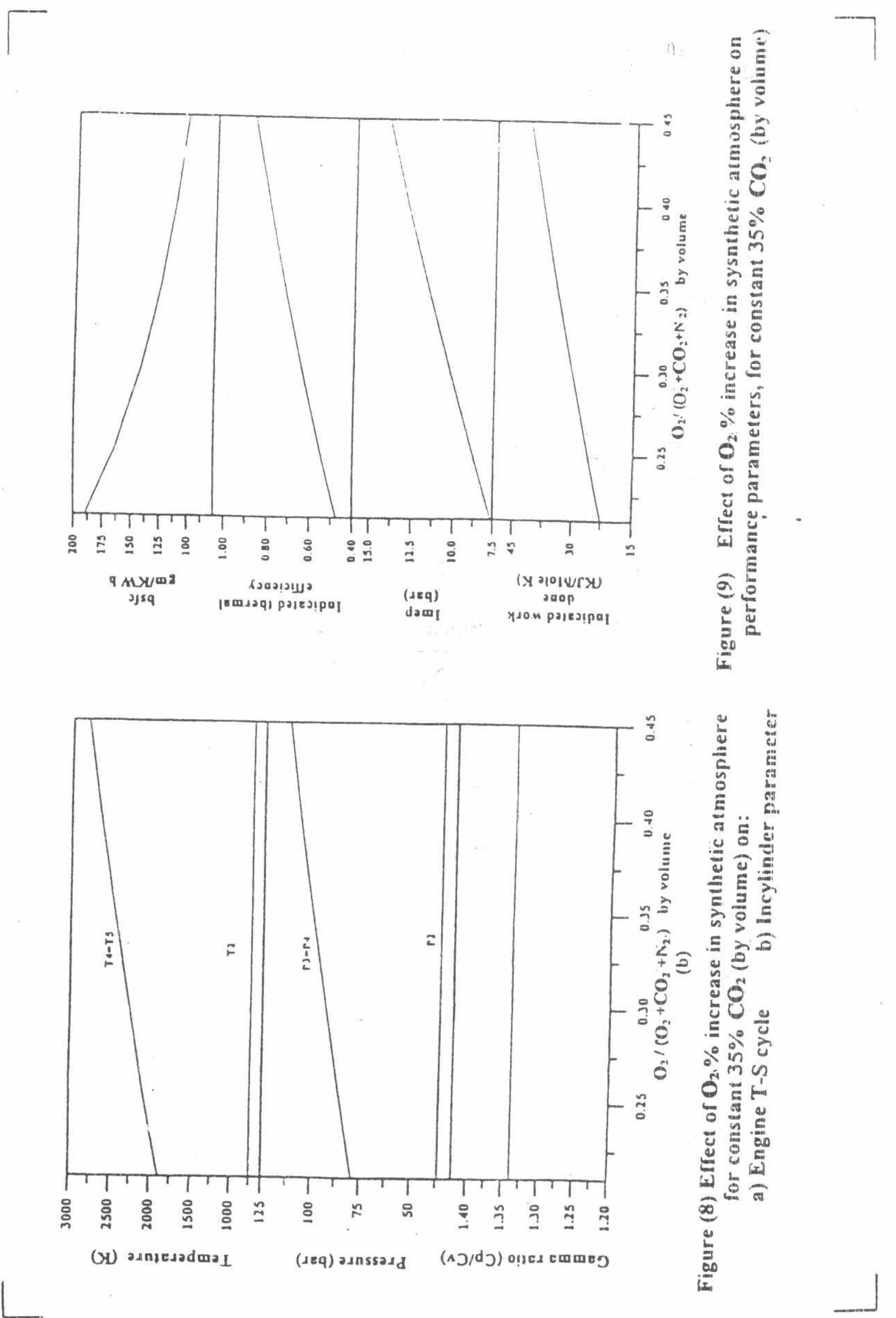




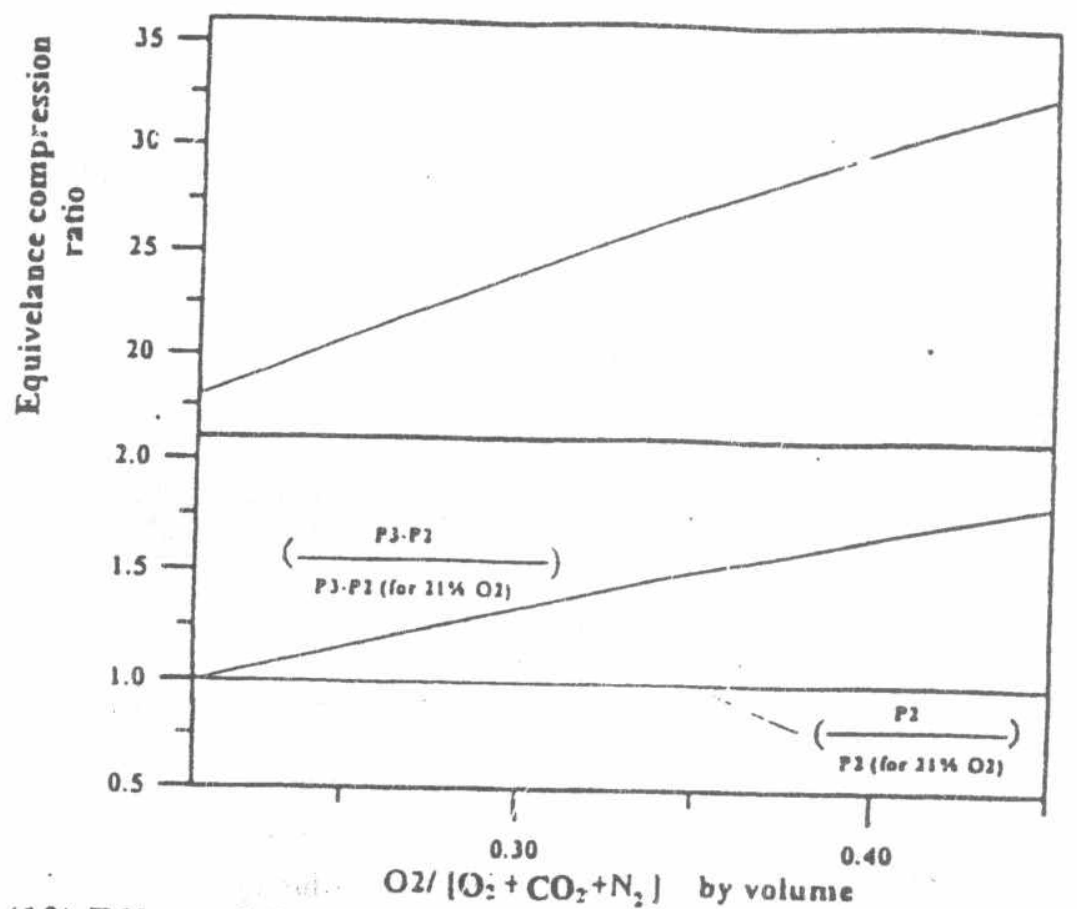

Figure (10) Effect of $\mathrm{O}_{2} \%$ increase beyond $21 \%$ by volume and predicting the effect ot compression ratio on the base of the maximume pressure of the cycle.

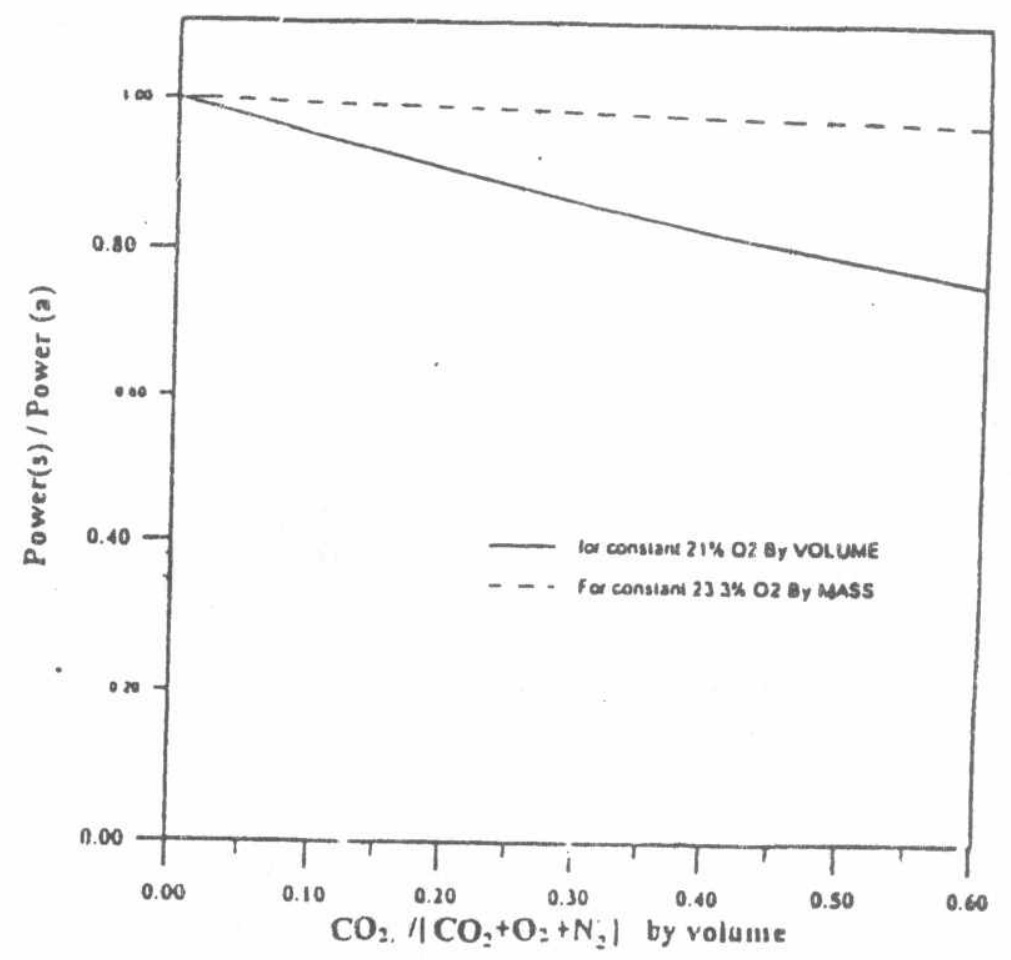

Figure (11) Effect of $\mathrm{CO}_{2} \%$ increase on Power(s)/Power(a), for synthetic atmosphere of constant $21 \% \mathrm{O}_{2}$ by volume, and $23.3 \% \mathrm{O}_{2}$ by mass. 


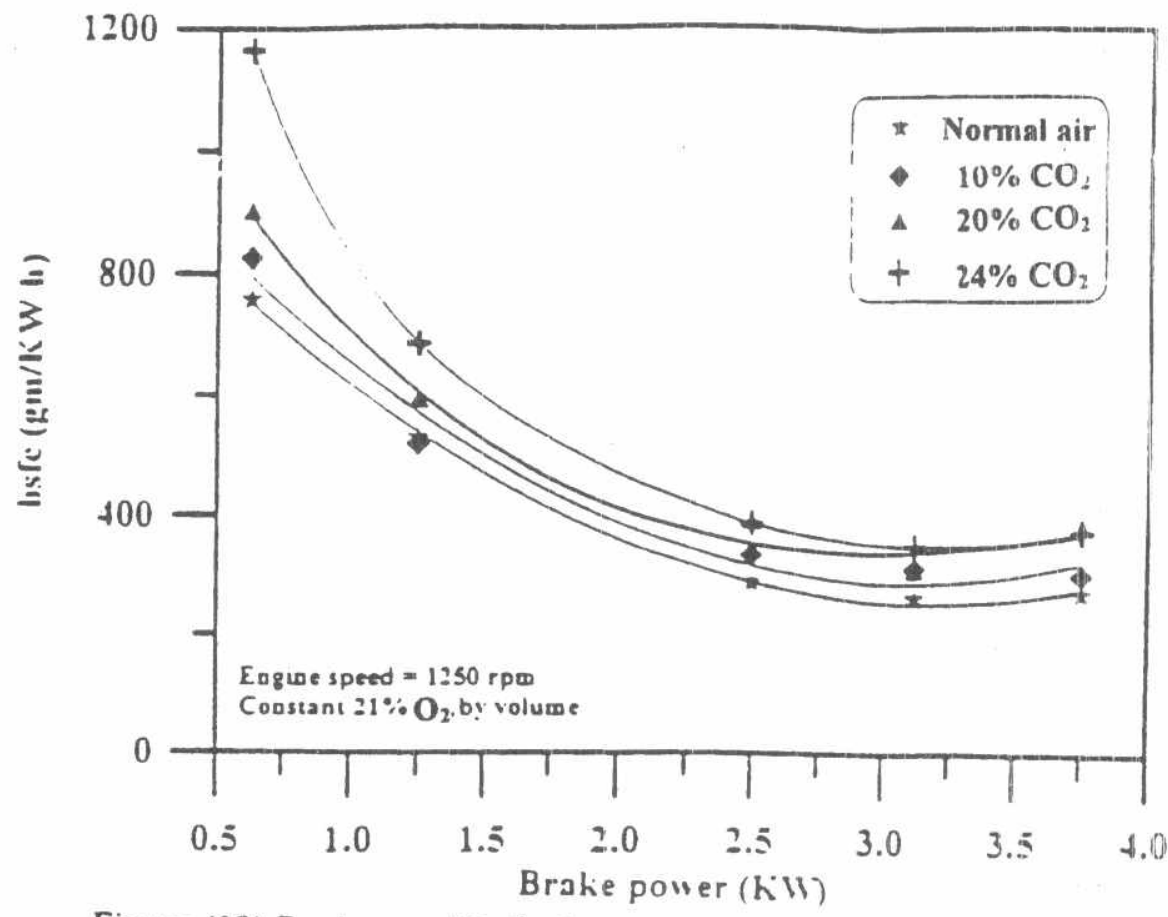

Figure (12) Brake specific fuel consumption against Bratie power for synthetic atmospbere of constant $21 \% \mathbf{O}_{2}$ ? volume.

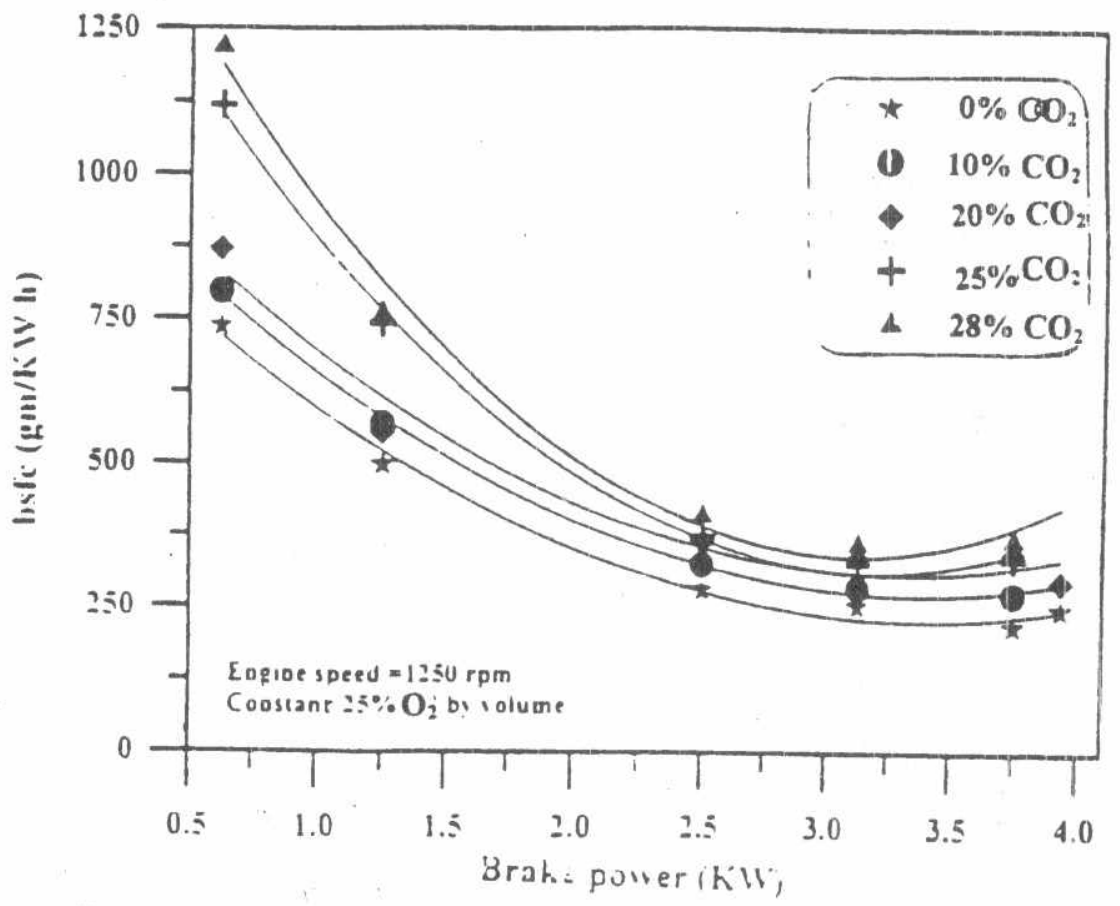

Figure (13) Bratie specific fuel consumption against brake power for synthetic atmosphere of constant $25 \% \mathrm{O}_{2}$ by volume 